\title{
MULTI-STOREY COMPOSITE FRAMED-STRUCTURES DUE TO EDGE-COLUMN LOSS
}

\author{
Guo-qiang Li ${ }^{1,2}$, Jing-zhou Zhang ${ }^{1, *}$ and Jian Jiang ${ }^{3}$ \\ 'College of Civil Engineering, Tongji University, Shanghai, China \\ ${ }^{2}$ State Key Laboratory for Disaster Reduction in Civil Engineering, Shanghai, China \\ ${ }^{3}$ Jiangsu Key Laboratory of Environmental Impact and Structural Safety in Engineering, China University of China University of Mining and Technology, Xuzhou, China \\ *(Corresponding author: E-mail: 1410206zhangjingzhou@tongji.edu.cn)
}

\section{A B S T R A C T}

This paper proposes an analytical method to predict the progressive collapse resistance of multi-storey composite framed-structures due to different scenarios of edge column loss. These include the removal of edge-intermediate (EI) or edge-corner (EC) column. The proposed method accounts for the tensile membrane action of slabs and vierendeel effect of the steel frames. The reliability of the proposed method is verified against validated numerical simulations. Parametric studies show that for EI column loss scenario, the vierendeel effect increases the plastic capacity of the structure but has limited influence on the ultimate capacity. However, the vierendeel effect significantly enhances the structural resistance against EC column loss $(>60 \%)$. It is thus over conservative to determine the progressive collapse resistance of multi-storey structures based on that of single-storey structures where no vierendeel effect is considered. Catenary action in steel beams has not noticeably developed under the removal of a corner column. In this case, it is recommended to calculate the ultimate bearing capacity of structures under a corner column removal according to the yield-line theory.
ART I CLE HISTORY

$\begin{array}{ll}\text { Received: } & \text { 12 February } 2019 \\ \text { Revised: } & \text { 24 May } 2019 \\ \text { Accepted: } & \text { 5 September } 2019\end{array}$

\section{K E Y W O R D S}

Collapse resistance;

Multi-storey;

Composite framed-structure;

Catenary action;

Vierendeel effect

\section{Introduction}

The concern with collapse resistance and robustness enhancement of buildings in structural design is initiated due to the accidental collapse event of Ronan Point tower in UK (1968), triggered by an explosion-induced loss of corner column at eighteenth storey [1]. Research efforts have been subsequently refocused and intensified following the collapse of Alfred P. Murrah building [2] and World Trade Center Towers [3] in USA. These events signify a growing potential for engineering buildings to suffer from extreme actions such as fire, explosion and impact, wherein they are prone to globally collapse without sufficient robustness even due to a limited local failure (i.e. disproportionate collapse). Hence, mitigating the susceptibility of structures against disproportionate collapse is of great importance in view of the potential casualties and property losses in case of collapse.

Composite framed-structures with steel skeletons and concrete floor systems have been widely used in various buildings due to their high constructional efficiency and excellent seismic performance [4]. In the case of a column loss, tensile membrane actions in reinforced-concrete slabs and catenary actions in steel beams are mobilized at large deflections to prevent the potential progressive collapse of composite framed-structures. Currently, experimental studies have been extensively launched to investigate the global performance of three-dimensional composite framed-structures due to a column loss [5-8]. Column removal tests by Johnson et al. [5] indicated that common composite framed-structures generally had significant capabilities to redistribute loads even without particular construction measures against progressive collapse. However, the ultimate bearing capacities of these structures failed to satisfy those required under the extreme event. In the experiments by $\mathrm{Fu}$ et al. [8], the effects of the composite action degree between slabs and beams, slab aspect ratio and boundary condition of the substructure on the progressive collapse resistance were investigated. It was concluded that the capability of vertical load redistribution was mainly influenced by the slab aspect ratio and connection ductility. Composite action had limited effect on the collapse resistance of substructures. Considering the huge financial cost of experimental studies, numerical analyses on the progressive collapse resistance of composite framed-structures have been successively carried out [9-12]. In the simulation models from Alashker et al. [11], the effects of structural parameters including steel deck thickness, slab reinforcement and the number of bolts in the shear tab on the behavior of structural systems were studied. It was found that the collapse resistance of structures was mainly provided by the steel deck. Increasing the number of bolts failed to significantly enhance the overall collapse resistance. Li et al. [12] numerically studied the robustness of a composite framed-structure in several column loss scenarios (external and interior columns in lower, middle and upper floors). The results revealed that compared with the lower-storey column loss, less robustness against progressive collapse was found in the upper-storey column loss scenario.

Research involving robustness analysis essentially aim to facilitate the structural safety design in practice. However, when the structural parameters change, relaunching the experimental and numerical investigations can be costly. Hence analytical method with simple calculations is more necessary to quantitatively guide the structural safety design. Such analytical studies focusing on the collapse resistance of composite framed-structures are relatively rare in the literature [13-16]. Izzuddin et al. [13] proposed an assessment framework to investigate the robustness of composite framed-structures due to an edge-intermediate column loss, wherein the structure was simplified to steel-concrete composite beams which facilitated its application in practical engineering. However, it failed to fully account for the beneficial effect of tensile membrane action in the floor systems, thus leading to less accuracy of the method to certain extent. Li et al. [14] analytically dealt with the collapse resistance of composite framed-structures due to an edge-intermediate column loss, wherein the contribution percentage of the slab and steel skeleton to the total resistance of the structure were quantified, respectively. However, the objective of their research was limited to single-storey structures, wherein the conclusions were questionable for multi-storey structures. Fig. 1 shows the difference of bending moment distribution between typical single-storey and multi-storey (taking two-storey

for example) structures due to a side column loss. It can be seen that for two-storey framed-structures, bending moment along beam section reverses its direction near the beam-column connection. The positive bending moment emerging at the beam end therefore increases the effective bending stiffness of the beam. This phenomenon, named as vierendeel effect, can enhance the plastic bearing capacity of two-storey framed-structures to more than twice that of corresponding single-storey framed-structures.

In general, analytical approaches on collapse resistance of composite framed-structures, accounting for both tensile membrane actions in floor systems and vierendeel effect in steel skeletons are rare. What's more, compared with the edge-intermediate and interior column loss scenarios, the edge-corner column loss scenario is always ignored considering its small probability of occurrence. These limitations in recent research impede the development of structural safety design of multi-storey buildings.

Accordingly, this paper proposed an energy-based method to directly predict the behavior of multi-storey composite framed-structures consisting of steel beams and concrete slabs due to an edge-column loss. It includes the removal of edge-intermediate (EI) or edge-corner (EC) column. The membrane action in the concrete floor systems and vierendeel effect in the multi-storey steel frames were fully considered. Simplified resistance-displacement curves were proposed to capture the primary mechanical features of structures at large deflections. The reasonability and 
reliability of the proposed analytical method were verified against validated numerical analyses.

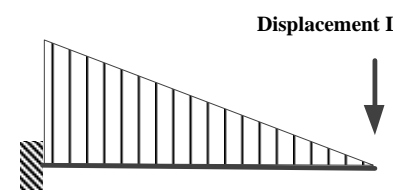

(a) Bending moment distribution in single-storey framed-structures

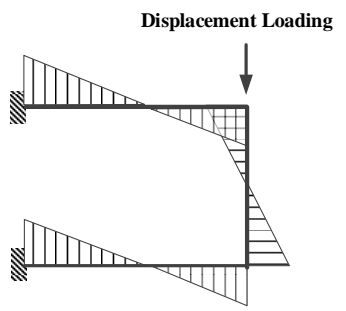

(b) Bending moment distribution in two-storey framed-structures

Fig. 1 Development of vierendeel effect in two-storey framed-structures due to a side

$$
\text { column loss }
$$

\section{Analytical method}

\subsection{Model simplification}

To evaluate the robustness of a structure subjected to an edge column loss, the most reasonable approach is to directly investigate the global behavior of the remaining structure. To save the computational cost but without missing the key mechanical characteristics, a beam-slab substructure adjacent to the removed column was extracted and investigated for two removal scenarios: edge-intermediate (EI) column and edge-corner (EC) column, as shown in Fig.

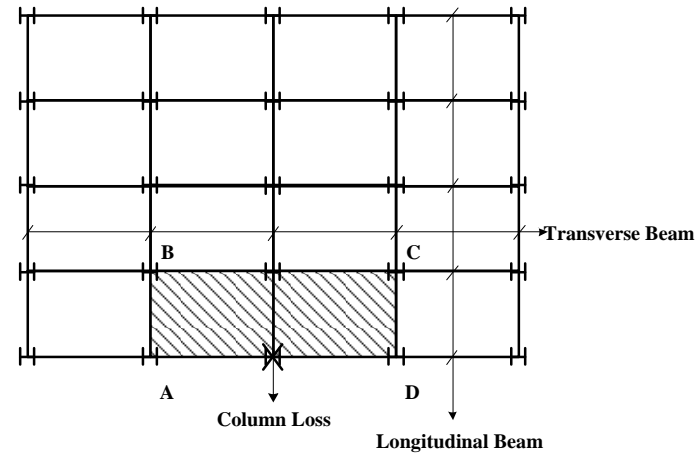

(a) Original structure
2 and Fig. 3, respectively. For the scenario of EI column loss, the substructure $\mathrm{ABCD}$ was extracted from the whole structure, wherein the boundary conditions for edges $\mathrm{AB}, \mathrm{BC}$ and $\mathrm{CD}$ are assumed to be fully restrained due to surrounding substructures. Edge AD was assumed to be free. In the case of EC column loss, analogously, the edges $\mathrm{CD}$ and $\mathrm{CF}$ were postulated to be fixed, and the edges DE and EF were left to be free. The reasonability of this simplification has been verified by Zhang and $\mathrm{Li}$ [16], wherein the resistance-displacement curves for the full structures and extracted substructures due to a middle column loss were compared. It was concluded that the plastic bearing capacity of the whole structure was slightly smaller than that of the simplified substructure. At large deflections, the progressive collapse resistance for the substructure agreed well with that of the corresponding full structure. Therefore, in the following sections, the full structure was represented by the idealized corresponding substructure. This study focused on the steel moment frame with flat concrete slab (the steel deck being excluded), where all steel beams were fully welded to the columns and no secondary beam was considered. The strength of the welding was identical to that of the steel beam.

\subsection{Edge-intermediate (EI) column removal scenario}

A tri-linear resistance-displacement curve was analytically determined by Li et al. [14] for single-storey substructures due to an EI column loss. This curve is found to be also suitable for multi-storey substructures in the event of an EI column loss. As shown in Fig. $4, F_{y}$ and $F_{u}$ are the plastic and ultimate bearing capacity of the substructure, respectively. The determination of $v_{A}$ and $v_{B}$ was described in reference [14]. The failure displacement $v_{c}$ can be calculated from the current building regulation [17]. However, herein the displacement $v_{c}$ was directly obtained from numerical analyses to achieve afair comparison between the numerical and analytical ultimate bearing capacity. For given $F_{y}$ and $F_{u}$, the resistance-displacement curve can be determined for multi-storey substructures due to an EI column loss. The plastic and ultimate bearing capacity of multi-storey substructures were determined as follows

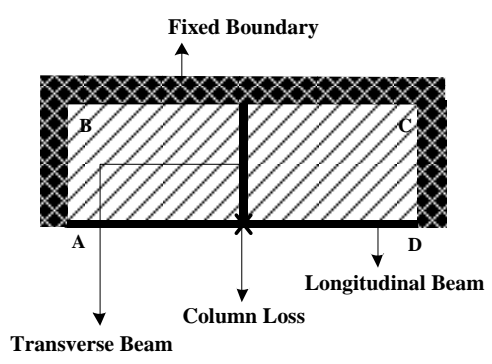

(b) Simplified substructure

Fig. 2 Simplified model for edge-intermediate (EI) column loss

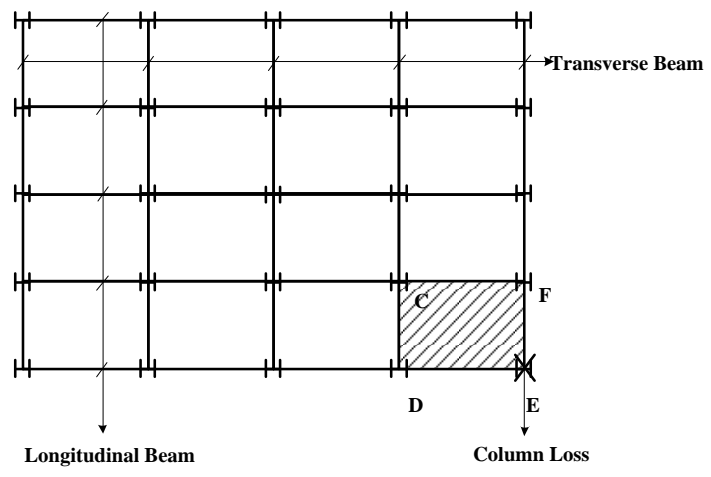

(a) Original structure

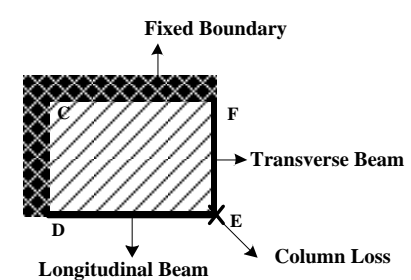

(b) Simplified substructure

Fig. 3 Simplified model for edge-corner (EC) column loss

2.2.1. Plastic bearing capacity of multi-storey substructures due to an EI column loss

Fig. 5 illustrates the yield line pattern for single-storey substructures. The positive plastic hinge of the steel beam in $\mathrm{Y}$-direction was not accounted for considering that the boundary condition at beam end $\mathrm{C}$ is free. However, for the yield line pattern of multi-storey substructures shown in Fig. 6, positive 
moment hinges were assumed to emerge at the end of the transverse beams $\mathrm{CG}$ and $\mathrm{DH}$, due to the rotational restraints provided by the column CD (shown in Fig. 7). The deflection at the removed column location (Point D) was assumed to be 1. Based on the yield-line theory, the total internal work done due to the rotation in plastic hinges and along the yield lines is given by (the curved negative yield lines $\mathrm{A}_{1} \mathrm{~A}$ and $\mathrm{E}_{1} \mathrm{E}$ are assumed to be linear, with length $l$ )

$$
W_{i n}=\sum_{i=1}^{N}\left(\frac{2 \alpha_{i} M_{y i} L_{i}}{l_{i}}+\frac{2 M_{x i} l_{i}}{\alpha_{i} L_{i}}+\frac{2 M_{x i}^{\prime} l_{i}}{\alpha_{i} L_{i}}+\frac{2\left(M_{L N i}+M_{L P i}\right)}{\alpha_{i} L_{i}}+\frac{M_{T N i}+M_{T P i}}{l_{i}}\right)
$$

where $N$ is the total storey number; $i$ is the number of a certain storey; $M_{x i}$ and $M_{x i}$ are the negative and positive yield bending capacity per unit width of slabs about $Y$ direction at storey $i$, respectively; $M_{y i}$ is the positive yield bending capacity per unit width of slabs about $X$ direction at storey $i ; M_{L N i}$ and $M_{L P i}$ are the negative and positive plastic capacity of beams in $X$ direction at storey $i$, respectively; $M_{T N i}$ and $M_{T P i}$ are the negative and positive plastic capacity of beams in $Y$ direction at storey $i$, respectively. The development of $M_{T P i}$ is dependent on the column plastic bending capacity. $M_{T P i}$ was determined as the minimum value of the plastic bending capacity of the transverse beam and column. The value of parameter $\alpha_{i}$ should be taken as no greater than 0.5 .

For a concentrated load, the work done by the external force is expressed as:

$W_{e x t}=F_{y}$

$F_{y}=\sum_{i=1}^{N}\left(\alpha_{i} B_{i}+\frac{A_{i}}{\alpha_{i}}+\frac{M_{T N i}+M_{T P i}}{l_{i}}\right)$

where

$A_{i}=2 \frac{M_{x i} l_{i}+M_{x i}^{\prime} l_{i}+M_{L N i}+M_{L P i}}{L_{i}} \quad B_{i}=2 \frac{M_{y i} L_{i}}{l_{i}}$

The parameter $\alpha_{i}$ can be determined according to the minimum load principle [18]:

$\frac{d F_{y}}{d \alpha_{i}}=0$

The solution to Eq. (5) is given by:

$\alpha_{i}=\sqrt{\frac{A_{i}}{B_{i}}}$

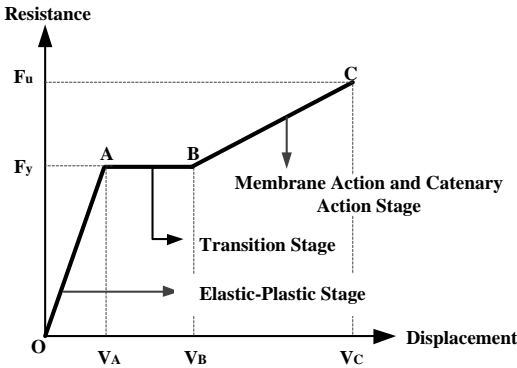

Fig. 4 Simplified resistance-displacement curve for multi-storey substructures due to an EI column loss [14]

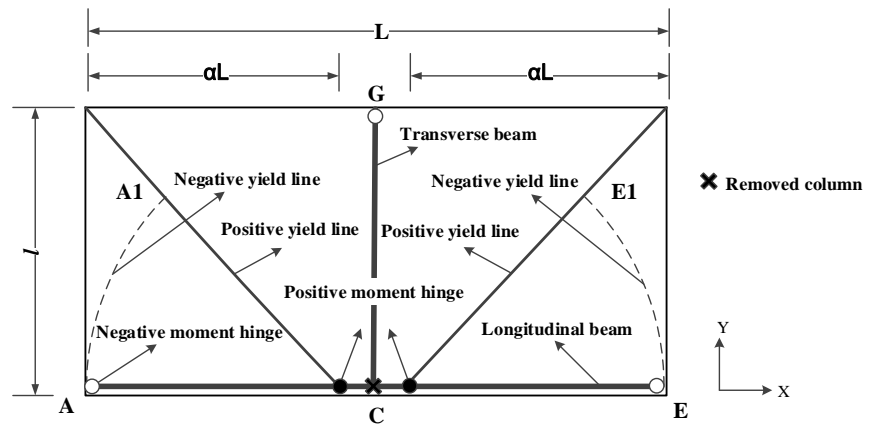

Fig. 5 Schematic of yield line pattern for single-storey substructures [14]

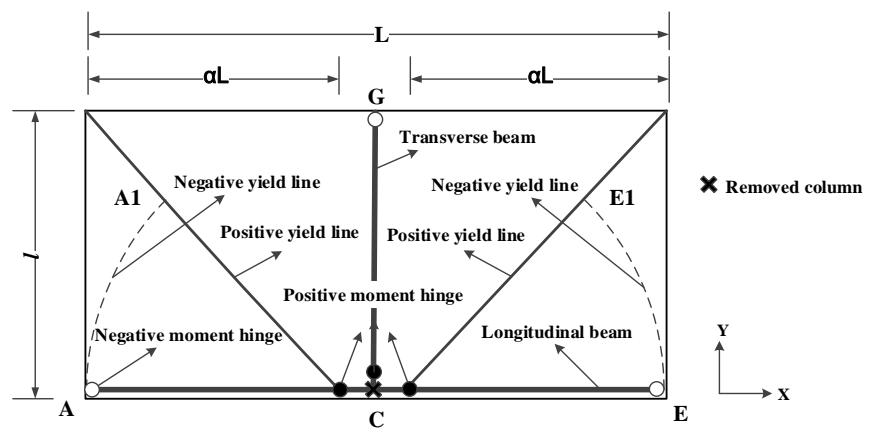

Fig. 6 Schematic of yield line pattern for multi-storey substructures

\subsubsection{Ultimate bearing capacity of multi-storey substructures due to an EI column loss}

The ultimate bearing capacity $F_{u}$ of multi-storey substructures due to an EI column loss was determined by simply summing up the capacity for each storey of the substructure, wherein the vierendeel effect was not accounted for The reason is shown in Fig. 8. The beam ends $\mathrm{C}$ and $\mathrm{D}$ can freely rotate due to the presence of plastic hinges at large deflections. At this moment, considering that the resisting mechanism gradually changes from bending action to catenary action in the steel beams, the ultimate bearing capacity for skeleton GCDH is essentially the sum of that for the two individual skeletons GC and HD. The detailed deduction process of ultimate bearing capacity for single-storey substructures due to an EI column loss is included in reference [14], which is derived based on the principle of minimum potential energy [19]. The ultimate bearing capacity $F_{u}$ for multi-storey substructures is directly given by:

$$
\begin{gathered}
F_{u}=\sum_{i=1}^{N}\left(C_{x e i}\left(T_{x i} l_{i}+2 F_{u L i}\right)+2 C_{y a i} T_{y i} L_{i} b_{i} \frac{v}{2 l_{i}}+2 C_{x a i} T_{x i l} l_{i} b_{i} \frac{v}{\alpha_{i} L_{i} L_{i}}+2 C_{y m i} M_{y i} \alpha_{i} \frac{L_{i}}{l_{i}}+2 C_{x m i} M_{x i} \frac{l_{i}}{\alpha_{i} L_{i}}+2 M_{x i}^{\prime} \frac{l_{i}}{\alpha_{i} L_{i}}\right)
\end{gathered}
$$

where $C_{x e i}$ represents the contribution due to extensions of rebar and steel beams at storey $i ; C_{y a i}$ and $C_{x a i}$ represent the effect of membrane force-induced bending moments at storey $i ; C_{y m i}$ and $C_{x m i}$ denote interactions between the tensile force and yield bending capacity of sections along yield lines at storey $i$. The detailed expressions of these parameters is included in reference [14].

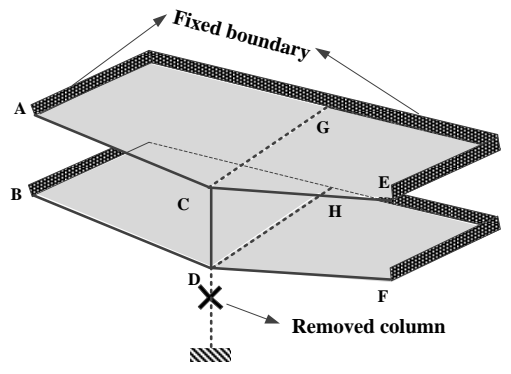

Fig. 7 Configuration of multi-storey substructures due to an EI column loss (taking a two-storey system for example) 


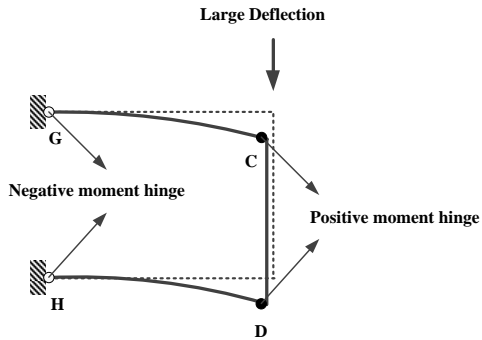

Fig. 8 Deformation configuration of skeleton GCDH at large deflections

\subsection{Edge-corner (EC) column removal scenario}

For a multi-storey substructure under an EC column loss, the plastic and ultimate bearing capacities were assumed to be identical in this study. This is because that in this scenario, the catenary action in cantilever steel beams fails to sufficiently develop due to its inadequate axial restraint. The resistance forthe substructures due to an EC column loss is incapable of apparently re-ascending at large deflections. The deduction process of ultimate bearing capacity in this case was elucidated as follows. Fig. 9 shows the yield line pattern for single-storey substructures due to an EC column loss, wherein positive moment hinges were not considered due to the free boundary condition of beam end T. For multi-storey substructures, however, positive moment hinges were assumed to exist at the beam end $\mathrm{T}$, considering the column-induced rotational restraints (shown in Fig. 10 and Fig. 11). Thedeflection at the location of the removed column (Point $U$ ) was assumed to be 1 . The total internal work done is given by:

$$
W_{i n}=\sum_{i=1}^{N}\left(\frac{M_{x i}^{\prime} l_{i}}{L_{i}}+\frac{M_{y i}^{\prime} L_{i}}{l_{i}}+\frac{M_{L N i}+M_{L P i}}{L_{i}}+\frac{M_{T N i}+M_{T P i}}{l_{i}}\right)
$$

For a concentrated load, the work done by the external force is given by:

$W_{e x t}=F_{y}$

Thus, the yield load is calculated as:

$F_{y}=\sum_{i=1}^{N}\left(\frac{M_{x i}^{\prime} l_{i}}{L_{i}}+\frac{M_{y i}^{\prime} L_{i}}{l_{i}}+\frac{M_{L N i}+M_{L P i}}{L_{i}}+\frac{M_{T N i}+M_{T P i}}{l_{i}}\right)$

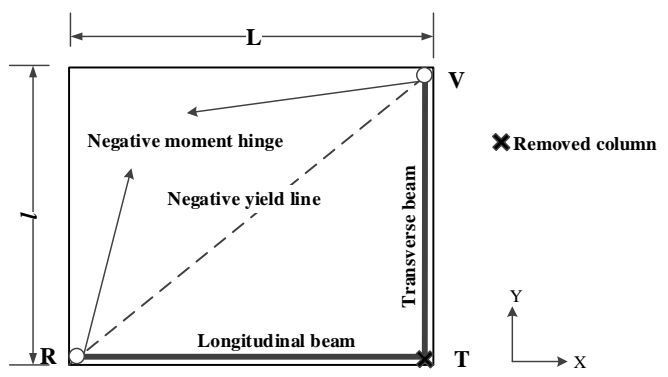

Fig. 9 Schematic of yield line pattern for single-storey substructures due to an EC

column loss

\section{Verifications}

The multi-storey framed-structure is represented by the two-storey framed-structure in the numerical models for simplicity. In the following sections, the notations "IntT" and "IntS" were used to simply represent the case for two-storey and single-storey substructures subjected to an EI column loss, respectively. The notations "CorT" and "CorS" were used to represent the case for two-storey and single-storey substructures subjected to an EC column loss, respectively. The reliability and effectiveness of the finite element approaches being used in the numerical models have been validated against several experiments by Guo et al. [7] and. Yi et al. [20]. The Finite Element models were established in ABAQUS [21]. Eight-node solid element was used to simulate concrete slab. Two-node truss element was employed to model rebar. Steel columns and beams are modeled by Four-node shell element. "Embedded" Command was used to connect the rebar and concrete slab. "Tie" Command was employed to connect the steel beam and concrete slab. All steel members, including the beams and columns were merged as a new assembly to achieve rigid beam-column connections. The stress-strain relationship of steel was assumed to be bi-linear. The ductile damage model was used to account for the failure of steel. The concrete was modelled by plastic damage model, wherein the compressive stress-inelastic strain and tensile stress-cracking strain relationships were defined to account for the compressive and tensile behavior of concrete, respectively. The details are included in reference [14]

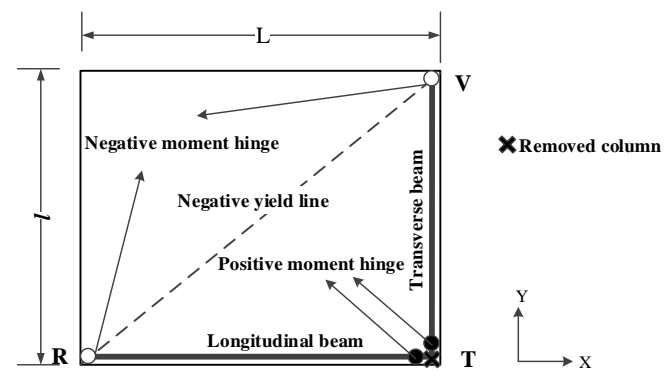

Fig. 10 Schematic of yield line pattern for multi-storey substructures due to an EC column loss

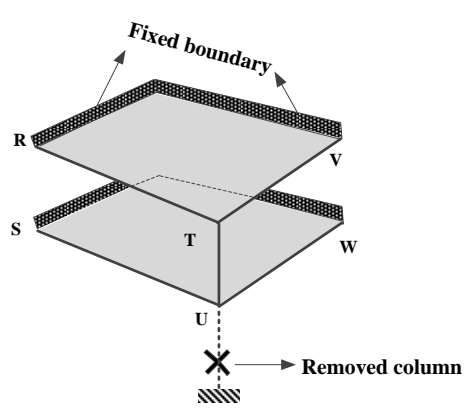

Fig. 11 Configuration of multi-storey substructures due to an EC column loss (taking a two-storey system for example)

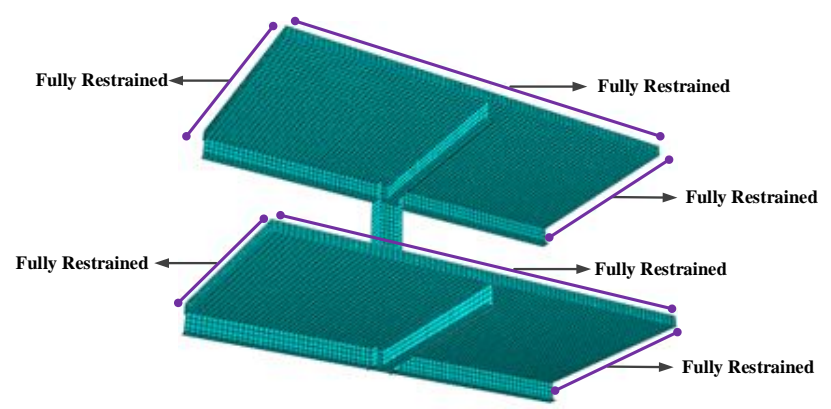

Fig. 12 Boundary conditions and mesh size of the finite element models for the IntT-series substructure

\subsection{Edge-intermediate (EI) column removal scenario}

A total of 13 numerical models for the IntT-series substructures were established. The boundary conditions and mesh size of the numerical models are shown in Fig. 12. Three edges (including the beam ends) of the substructure were fixed. A displacement-control loading was imposed at the predefined column-loss position of the substructure. The section dimension of the transverse beams is the same with that of the longitudinal beams. The slab has identical reinforcement in transverse and longitudinal directions. The material properties in the beam are the same to those measured in the experiment [7]. The same materials were used for the steel beams and columns. The details of the design parameters are shown in Table. 1. The substructure IntT1 is the baseline specimen. Compared with IntT1, the short span of IntT2, IntT3 and IntT4 are reduced by $12.5 \%$, increased by $12.5 \%$ and $25 \%$, respectively. The slab thickness of IntT5, IntT6 and IntT7 are reduced by $25 \%$, increased by $25 \%$ and $50 \%$, respectively. The reinforcement 
Table. 1

Details of the IntT-series substructures

\begin{tabular}{|c|c|c|c|c|c|c|}
\hline \multirow{2}{*}{ No. } & \multirow{2}{*}{ Variable } & \multirow{2}{*}{ Planar Size $(L \times l)$} & \multirow{2}{*}{ Slab Thickness } & \multicolumn{2}{|c|}{ Reinforcement } & \multirow{2}{*}{ Beam Section } \\
\hline & & & & Top & Bottom & \\
\hline IntT1 & Baseline specimen & $4000 \times 2000$ & 100 & $\Phi 12 @ 120$ & $\Phi 12 @ 180$ & $200 \times 100 \times 5.5 \times 8$ \\
\hline IntT2 & & $4000 \times 1750$ & 100 & $\Phi 12 @ 120$ & $\Phi 12 @ 180$ & $200 \times 100 \times 5.5 \times 8$ \\
\hline IntT3 & Aspect ratio & $4000 \times 2250$ & 100 & $\Phi 12 @ 120$ & Ф12@180 & $200 \times 100 \times 5.5 \times 8$ \\
\hline IntT4 & & $4000 \times 2500$ & 100 & $\Phi 12 @ 120$ & $\Phi 12 @ 180$ & $200 \times 100 \times 5.5 \times 8$ \\
\hline IntT5 & & $4000 \times 2000$ & 75 & Ф12@120 & $\Phi 12 @ 180$ & $200 \times 100 \times 5.5 \times 8$ \\
\hline IntT6 & Slab thickness & $4000 \times 2000$ & 125 & $\Phi 12 @ 120$ & Ф12@180 & $200 \times 100 \times 5.5 \times 8$ \\
\hline IntT7 & & $4000 \times 2000$ & 150 & $\Phi 12 @ 120$ & Ф12@180 & $200 \times 100 \times 5.5 \times 8$ \\
\hline IntT8 & & $4000 \times 2000$ & 100 & Ф14@120 & Ф14@180 & $200 \times 100 \times 5.5 \times 8$ \\
\hline IntT9 & Rebar diameter & $4000 \times 2000$ & 100 & Ф16@120 & Ф16@180 & $200 \times 100 \times 5.5 \times 8$ \\
\hline IntT10 & & $4000 \times 2000$ & 100 & $\Phi 10 @ 120$ & $\Phi 10 @ 180$ & $200 \times 100 \times 5.5 \times 8$ \\
\hline IntT11 & & $4000 \times 2000$ & 100 & $\Phi 12 @ 120$ & $\Phi 12 @ 180$ & $120 \times 100 \times 5.5 \times 8$ \\
\hline IntT12 & Beam section height & $4000 \times 2000$ & 100 & $\Phi 12 @ 120$ & $\Phi 12 @ 180$ & $160 \times 100 \times 5.5 \times 8$ \\
\hline IntT13 & & $4000 \times 2000$ & 100 & $\Phi 12 @ 120$ & $\Phi 12 @ 180$ & $240 \times 100 \times 5.5 \times 8$ \\
\hline
\end{tabular}

Note: Dimensions in $\mathrm{mm}$

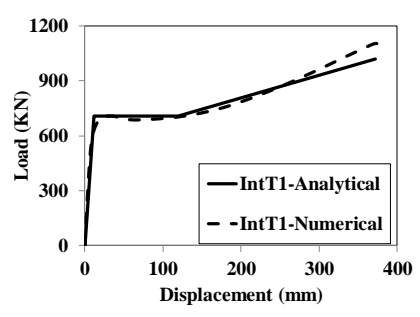

(a) IntT1

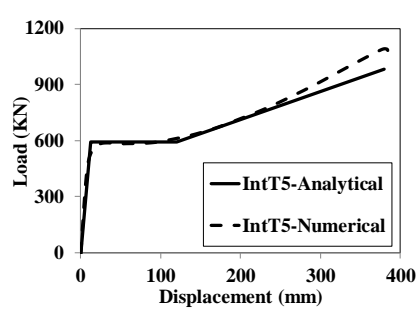

(e) IntT5

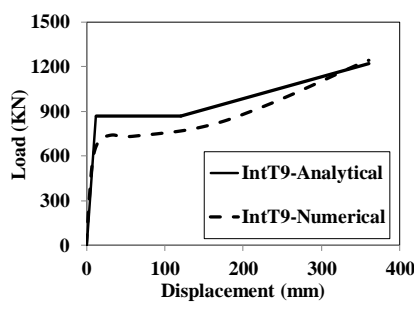

(i) IntT9

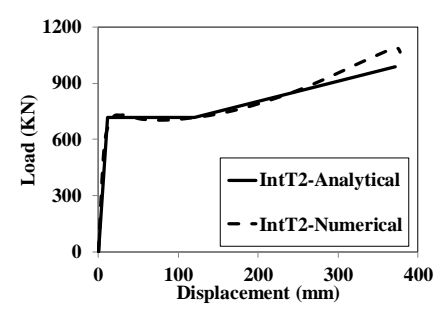

(b) IntT2

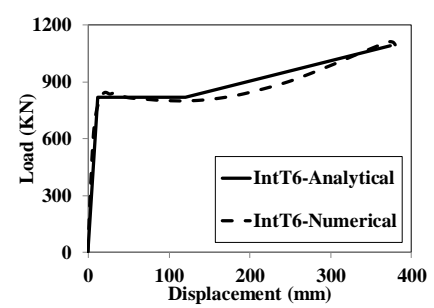

(f) IntT6

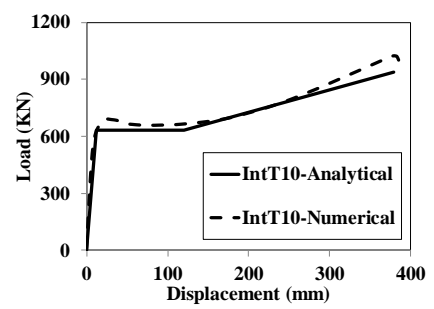

(j) IntT10

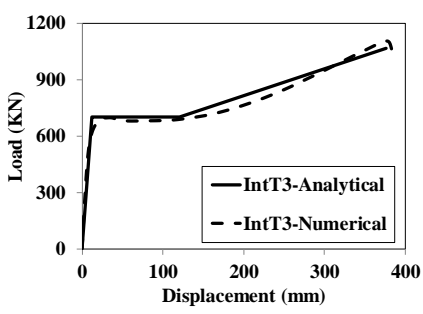

(c) IntT3

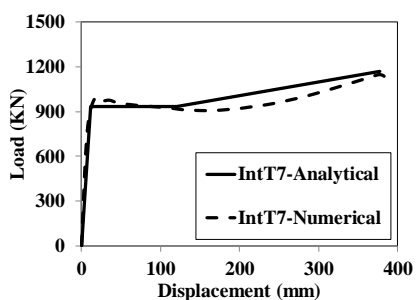

(g) IntT7

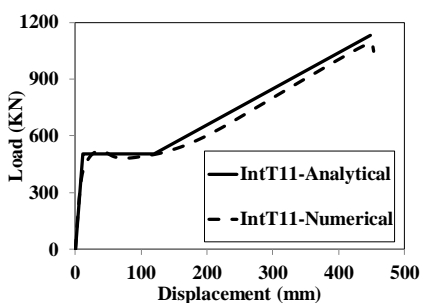

(k) IntT11

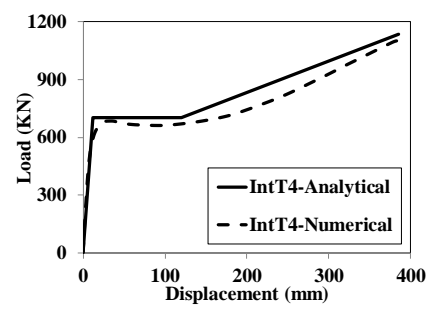

(d) IntT4

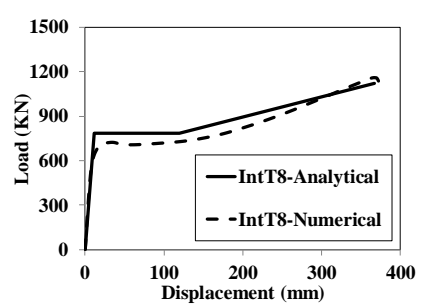

(h) IntT8

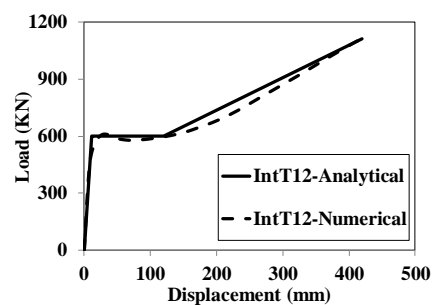

(1) IntT12

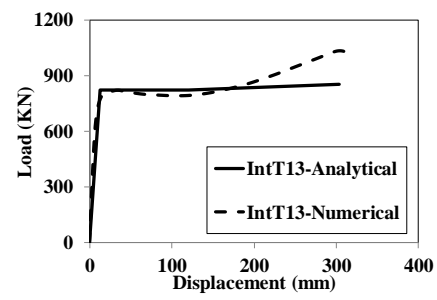

(m) IntT13 
Table 2

Relative errors of the analytical ultimate bearing capacity for IntT-series substructures

\begin{tabular}{cccc}
\hline No. & $\begin{array}{c}\text { Numerical Ultimate } \\
\text { Capacity }(\mathrm{kN})\end{array}$ & $\begin{array}{c}\text { Analytical Ultimate } \\
\text { Capacity }(\mathrm{kN})\end{array}$ & $\begin{array}{c}\text { Relative } \\
\text { Errors }(\%)\end{array}$ \\
\hline IntT1 & 1103.8 & 1020.3 & $7.6 \%$ \\
IntT2 & 1086.9 & 989.3 & $9.0 \%$ \\
IntT3 & 1103.6 & 1066.5 & $3.4 \%$ \\
IntT4 & 1100.2 & 1133.6 & $-3.0 \%$ \\
IntT5 & 1092.5 & 981.0 & $10.2 \%$ \\
IntT6 & 1111.9 & 1092.9 & $1.7 \%$ \\
IntT7 & 1148.0 & 1172.1 & $-2.1 \%$ \\
IntT8 & 1162.7 & 1119.7 & $3.7 \%$ \\
IntT9 & 1242.8 & 1220.5 & $1.8 \%$ \\
IntT10 & 1023.9 & 939.7 & $8.2 \%$ \\
IntT11 & 1089.6 & 1130.2 & $-3.7 \%$ \\
IntT12 & 1108.7 & 1114.0 & $-0.5 \%$ \\
IntT13 & 1034.4 & 853.9 & $17.5 \%$ \\
\hline
\end{tabular}

ratio of IntT8, IntT9 and IntT10 are increased by $36.1 \%$ and $77.8 \%$, reduced by $30.6 \%$, respectively. The beam section height of IntT11, IntT12 and IntT13 are reduced by $40 \%$ and $20 \%$, increased by $20 \%$, respectively. The central distance between the two concrete slabs is $1.8 \mathrm{~m}$. The section dimension of the steel column is $250 \mathrm{~mm}$ (section height) $\times 200 \mathrm{~mm}$ (section width) $\times 16 \mathrm{~mm}$ (flange thickness) $\times 12 \mathrm{~mm}$ (web thickness).

The reasonability of the simplified resistance-displacement curve in Section 2.2 is exhibited in Fig. 13. For the substructures IntT1-IntT13, the main mechanical features during large deflections can be captured by the tri-linear curve. The analytical method was found to provide relatively accurate predictions on both the plastic and ultimate bearing capacity of the substructures. However, for the substructures IntT8 and IntT9, the predicted plastic capacity was slightly greater than that for numerical analyses. This is because the reinforcement ratio of the substructures IntT8 and IntT9 are 36\% and $78 \%$ greater than that of IntT1, respectively. The slab of the two substructures were over-reinforced, and thus only partial rebar along yield lines sufficiently yields. In practice, however, the substructures with over-reinforced slab should be avoided.

To further quantify the difference between the numerical and analytical ultimate bearing capacity, a relative error is defined:

Relative error $_{j}(\%)=\frac{q_{j-\text { numerical }}-q_{j-\text { analytical }}}{q_{j-\text { numerical }}}$

where $q_{j-\text {-numerical }}$ is the numerically predicted ultimate bearing capacity; $q_{j-\text {-analytical }}$ is the analytically predicted ultimate bearing capacity.

Table. 2 shows the relative errors of the analytically predicted ultimate bearing capacity for the substructures IntT1-IntT13. It can be seen that the relative errors were generally within $10 \%$. However, a conservative error of $17.5 \%$ was found for the substructure IntT13. This is because the fracture-induced failure at the bottom flange prematurely occurred due to a large section height of the steel beams. At this limit state, the catenary action in steel beams had not sufficiently developed, wherein the enhancement of vierendeel effect on the resistance of the substructure IntT13 was not negligible. This resulted in somewhat conservative analytical predictions of ultimate bearing capacity compared with numerical results.

\subsection{Edge-corner (EC) column removal scenario}

A total of 13 numerical models for the CorT-series substructures were established. The boundary conditions and mesh size of the numerical models are shown in Fig. 14. Two edges (including the beam ends) of the substructure were fully restrained. The transverse beams and longitudinal beams have the same section dimensions. The slab has identical reinforcement in transverse and longitudinal directions. The material properties in the beam are the same to those measured in the experiment [7]. The same materials were used for the steel beams and columns. The details of the model parameters are shown in Table. 3. The central distance between the two concrete slabs is $1.8 \mathrm{~m}$. The section dimension of the steel column is $200 \mathrm{~mm}$ (section height) $\times 200 \mathrm{~mm}$ (section width) $\times 16 \mathrm{~mm}$ (flange thickness) $\times 12 \mathrm{~mm}$ (web thickness).

Table. 3

Details of the CorT-series substructures

\begin{tabular}{|c|c|c|c|c|c|c|}
\hline \multirow{2}{*}{ No. } & \multirow{2}{*}{ Variable } & \multirow{2}{*}{ Planar Size $(L \times l)$} & \multirow{2}{*}{ Slab Thickness } & \multicolumn{2}{|c|}{ Reinforcement } & \multirow{2}{*}{ Beam Section } \\
\hline & & & & Top & Bottom & \\
\hline CorT1 & Baseline specimen & $2000 \times 2000$ & 100 & $\Phi 12 @ 120$ & $\Phi 12 @ 180$ & $200 \times 100 \times 5.5 \times 8$ \\
\hline CorT2 & & $2000 \times 1750$ & 100 & Ф12@120 & $\Phi 12 @ 180$ & $200 \times 100 \times 5.5 \times 8$ \\
\hline CorT3 & Aspect ratio & $2000 \times 2250$ & 100 & $\Phi 12 @ 120$ & $\Phi 12 @ 180$ & $200 \times 100 \times 5.5 \times 8$ \\
\hline CorT4 & & $2000 \times 2500$ & 100 & $\Phi 12 @ 120$ & $\Phi 12 @ 180$ & $200 \times 100 \times 5.5 \times 8$ \\
\hline CorT5 & & $2000 \times 2000$ & 75 & Ф12@120 & $\Phi 12 @ 180$ & $200 \times 100 \times 5.5 \times 8$ \\
\hline CorT6 & Slab thickness & $2000 \times 2000$ & 125 & Ф12@120 & $\Phi 12 @ 180$ & $200 \times 100 \times 5.5 \times 8$ \\
\hline CorT7 & & $2000 \times 2000$ & 150 & $\Phi 12 @ 120$ & $\Phi 12 @ 180$ & $200 \times 100 \times 5.5 \times 8$ \\
\hline CorT8 & & $2000 \times 2000$ & 100 & Ф14@120 & $\Phi 14 @ 180$ & $200 \times 100 \times 5.5 \times 8$ \\
\hline CorT9 & Rebar diameter & $2000 \times 2000$ & 100 & Ф16@120 & $\Phi 16 @ 180$ & $200 \times 100 \times 5.5 \times 8$ \\
\hline CorT10 & & $2000 \times 2000$ & 100 & $\Phi 10 @ 120$ & $\Phi 10 @ 180$ & $200 \times 100 \times 5.5 \times 8$ \\
\hline CorT11 & & $2000 \times 2000$ & 100 & $\Phi 12 @ 120$ & $\Phi 12 @ 180$ & $120 \times 100 \times 5.5 \times 8$ \\
\hline CorT12 & Beam section height & $2000 \times 2000$ & 100 & $\Phi 12 @ 120$ & Ф12@180 & $160 \times 100 \times 5.5 \times 8$ \\
\hline CorT13 & & $2000 \times 2000$ & 100 & Ф12@120 & $\Phi 12 @ 180$ & $240 \times 100 \times 5.5 \times 8$ \\
\hline
\end{tabular}

Note: Dimensions in mm 


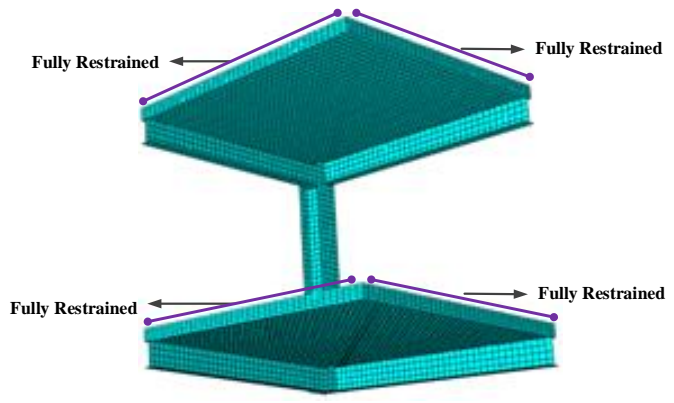

Fig. 14 Boundary conditions and mesh size of the finite element models for the

CorT-series substructure

As shown in Fig. 15, the analytical method generally provided reasonable predictions on the resistance of the substructures CorT1-CorT13 at large deflections. It was concluded that the numerical resistance-displacement curves for substructures CorT1-CorT13 differed significantly from those for Int $\mathrm{T}$-series substructures that they failed to apparently re-ascend at large deflections. This is because no sufficient axial restraint was provided to the cantilever steel beam in the case of EC column loss, and the catenary action was incapable of fully developing. It can be seen from Table 4 that for the substructure CorT7, the analytical ultimate bearing capacity of the substructures was larger than that for numerical analyses, with an error larger than $15 \%$. This is because the slab thickness for the substructure CorT7 is $50 \%$ larger than that of the baseline substructure CorT1. Thus, some concrete in the

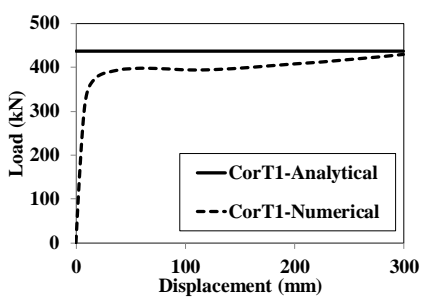

(a) CorT1

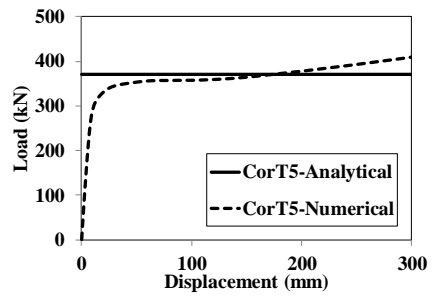

(e) CorT5

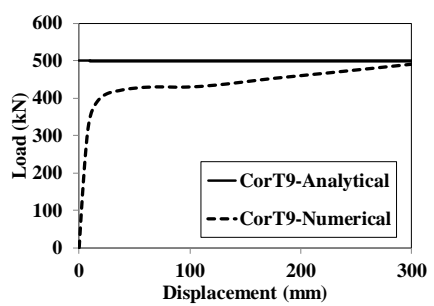

(i) CorT9

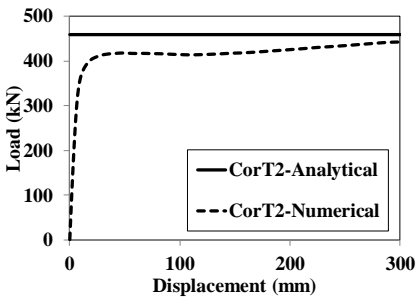

(b) CorT2

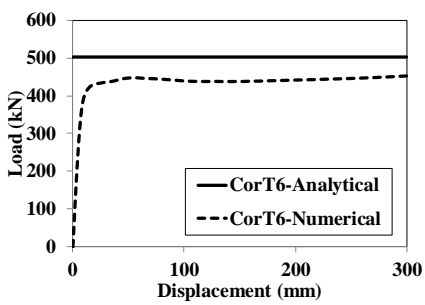

(f) CorT6

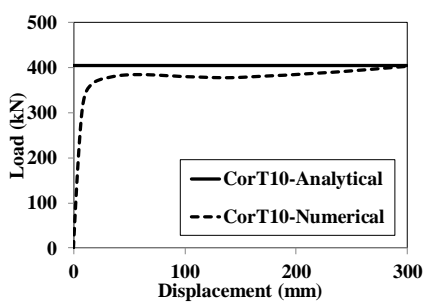

(j) CorT10

Table. 4

Relative errors of the analytical ultimate bearing capacity for CorT-series substructures

\begin{tabular}{cccc}
\hline No. & $\begin{array}{c}\text { Numerical Ultimate } \\
\text { Capacity }(\mathrm{kN})\end{array}$ & $\begin{array}{c}\text { Analytical Ultimate } \\
\text { Capacity }(\mathrm{kN})\end{array}$ & $\begin{array}{c}\text { Relative } \\
\text { Errors (\%) }\end{array}$ \\
\hline CorT1 & 429.4 & 436.8 & $-1.7 \%$ \\
CorT2 & 443.3 & 458.7 & $-3.5 \%$ \\
CorT3 & 410.7 & 420.4 & $-2.4 \%$ \\
CorT4 & 388.6 & 407.8 & $-4.9 \%$ \\
CorT5 & 409.9 & 370.8 & $9.5 \%$ \\
CorT6 & 453.3 & 502.8 & $-10.9 \%$ \\
CorT7 & 476.6 & 568.8 & $-19.4 \%$ \\
CorT8 & 459.5 & 468.3 & $-1.9 \%$ \\
CorT9 & 490.6 & 500.1 & $-1.9 \%$ \\
CorT10 & 402.2 & 405.2 & $-0.7 \%$ \\
CorT11 & 347.3 & 300.8 & $13.4 \%$ \\
CorT12 & 397.0 & 365.2 & $8.0 \%$ \\
CorT13 & 456.0 & 514.4 & $-12.8 \%$ \\
\hline
\end{tabular}

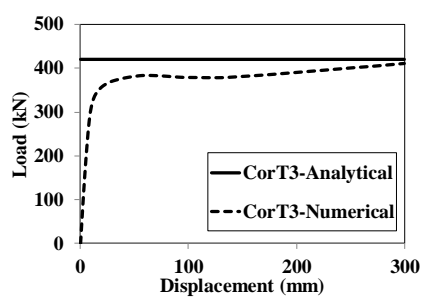

(c) CorT3

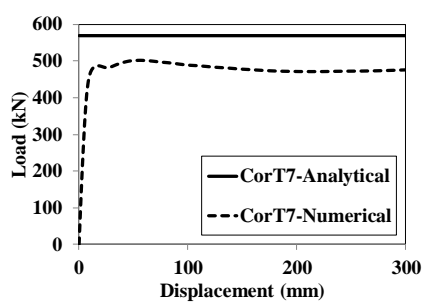

(g) CorT7

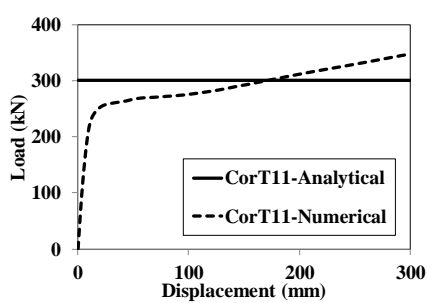

(k) CorT11

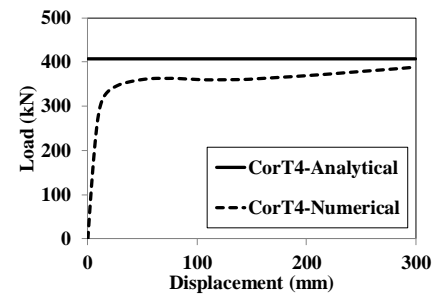

(d) CorT4

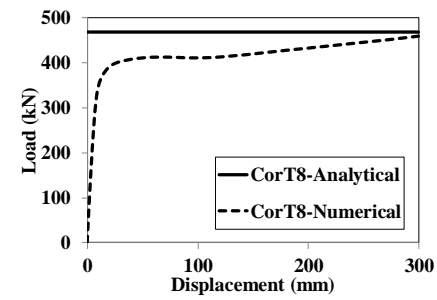

(h) CorT8

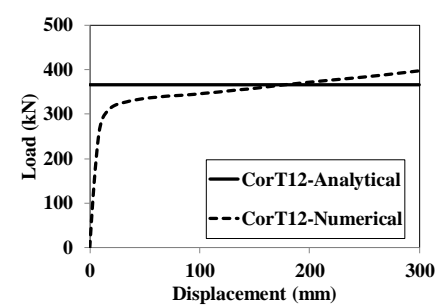

(1) CorT12

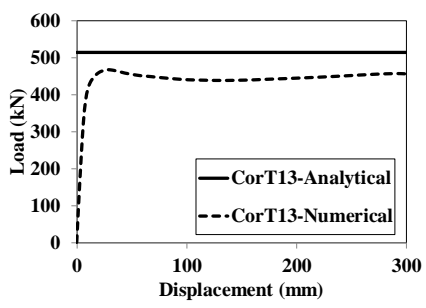

(m) CorT13 
slab section along the yield lines crushed at the early loading stage, and the plastic bearing capacity predicted from numerical analysis was somewhat lower than that from the analytical method. However, the load-displacement curve for the substructure CorT11 re-ascended more significantly compared with that of other substructures. It is because the substructure CorT11 has a relatively small beam height, enabling the catenary action in the steel beam to develop more easily. Therefore, the analytical predictions were conservative compared with numerical predictions for the substructure CorT11

\section{Discussions}

In Section 3, numerical models with various structural parameters were used to verify the accuracy of the analytical method. In this section. the contribution of vierendeel effect to the load bearing capacity of structures was discussed by a comparison of resistance-displacement curves between two-storey and single-storey framed-structures.

\subsection{Edge-intermediate (EI) column removal scenario}

For the IntS-series (single-storey) substructures, the details of the concrete slabs, steel beams, boundary conditions and mesh size of the numerical models were the same to those of the IntT-series (two-storey) substructures. A comparison of resistance-displacement curves for IntS-series and IntT-series substructures is shown in Fig. 16. To explicitly exhibit the potential existence of vierendeel effect in IntT-series substructures, the resistance for IntS-series substructures was doubled at the corresponding displacement. It can be seen that the resistance of the IntT-series substructures was greater than twice the resistance of the corresponding IntS-series substructures. However, the enhancement was not obvious. This is because in the case of EI column loss, the vierendeel effect merely developed in partial

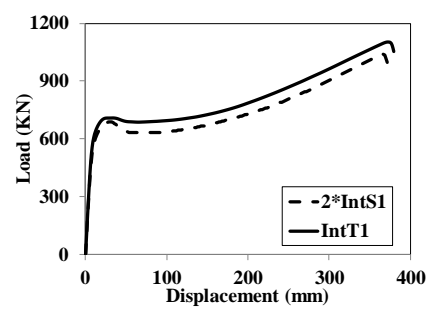

(a) IntS1 and IntT1

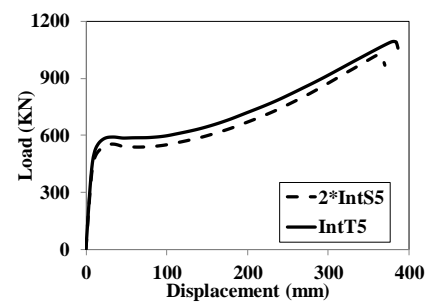

(e) IntS5 and IntT5

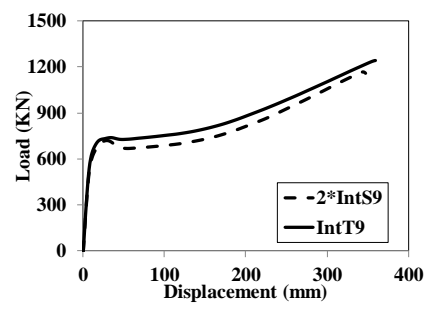

(i) IntS9 and IntT9

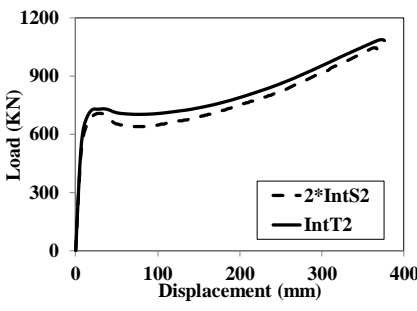

(b) IntS2 and IntT2

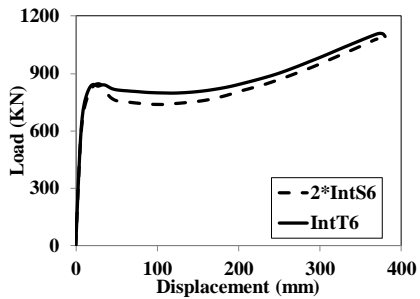

(f) IntS6 and IntT6

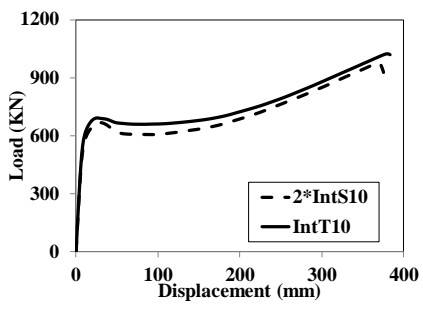

(j) IntS10 and IntT10

portion of steel skeletons. As shown in Fig. 7, the steel skeletons ACEBDF and GCDH were firstly extracted from the structure. The bending moment distributions of the skeleton ACE for IntS-series and IntT-series substructures were the same ( Fig. 17 (a) and (b)), and thus no enhancement existed in the skeleton ACEBDF. However, for the skeleton GCDH, due to the presence of the column $\mathrm{CD}$, positive plastic hinges developed at the beam end $\mathrm{C}$, resulting in increment in the effective bending stiffness for beams GC and HD since the point of contraflexure was shifted toward the fixed end G (Fig. 1). This yielded that the resistance for the skeleton GCDH became greater than twice that for the skeleton GC. Therefore, the vierendeel effect enhanced the resistance of two-storey substructures to a limited extent in the case of EI column loss.

\subsection{Edge-corner (EC) column removal scenario}

For the CorS-series (single-storey) substructures, the details of the concrete slabs, steel beams, boundary conditions and mesh size of the numerical models were the same to those of the CorT-series (two-storey) substructures. Fig. 18 shows a comparison of the resistance-displacement curves for CorS-series and CorT-series substructures. Similarly, the resistance for CorS-series substructures was doubled at the corresponding displacement. It was found that the resistance of the CorT-series substructures was remarkably greater than twice resistance of the corresponding CorS-series substructures. This is because the vierendeel effect developed in both stee skeletons RTUS and VTUW (shown in Fig. 11), which greatly enhanced the resistance of two-storey substructures (more than 60\%) in the case of EC column loss. Therefore, in practical engineering design, it is over conservative to calculate the ultimate bearing capacity of two-storey structures merely based on that of single-storey structures where no vierendeel effect is considered.

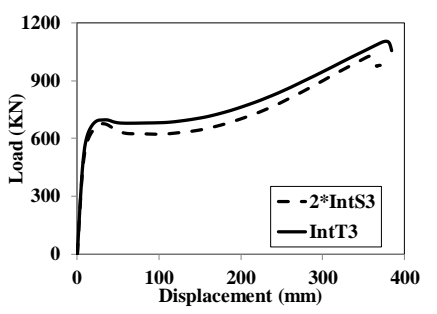

(c) IntS3 and IntT3

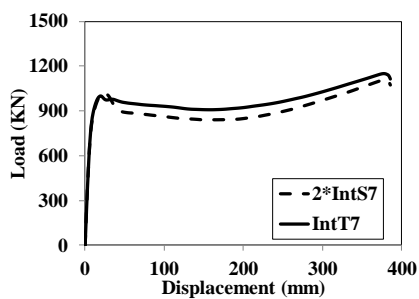

(g) IntS7 and IntT7

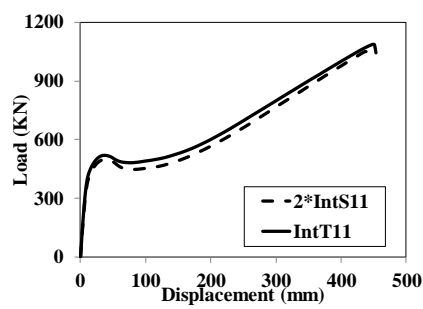

(k) IntS11 and IntT11

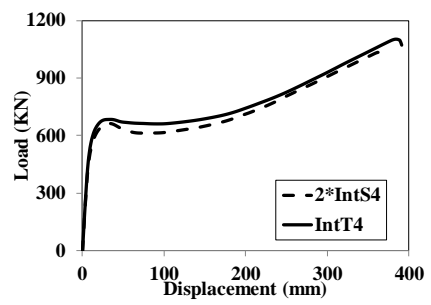

(d) IntS4 and IntT4

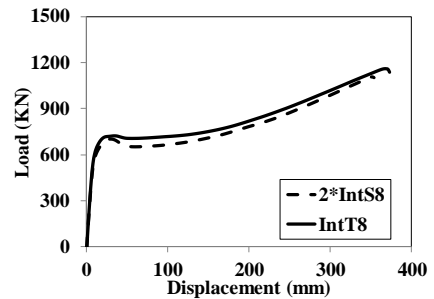

(h) IntS8 and IntT8

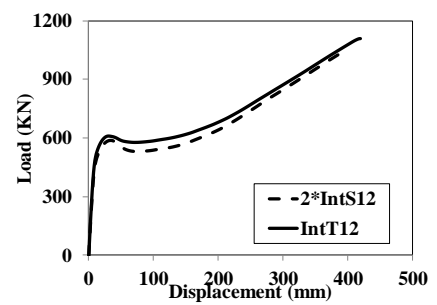

(1) IntS12 and IntT12

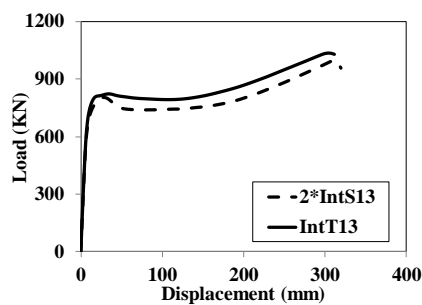

(m) IntS13 and IntT13 

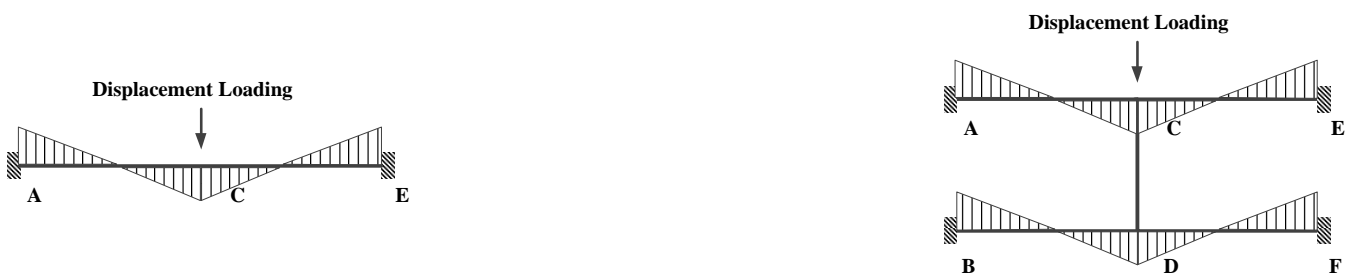

(a) Bending moment distribution in skeleton ACE for IntS-series substructure

(b) Bending moment distribution in skeleton ACEBDF for IntT-series substructure

Fig. 17 Schematic of vierendeel effect in two-storey substructures subjected to EI column loss

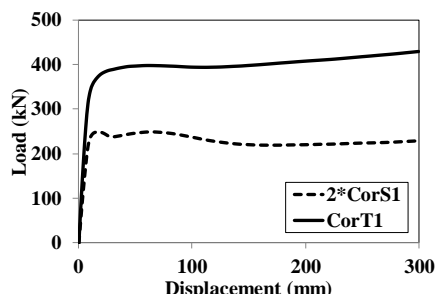

(a) CorS1 and CorT1

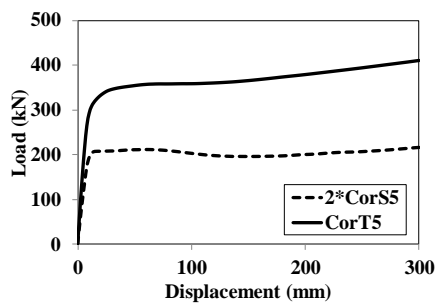

(e) CorS5 and CorT5

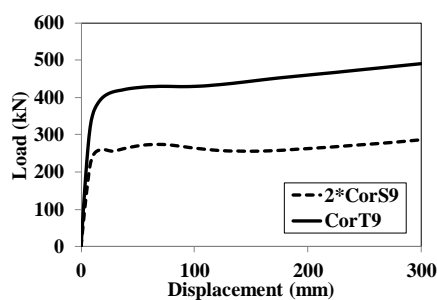

(i) CorS9 and CorT9

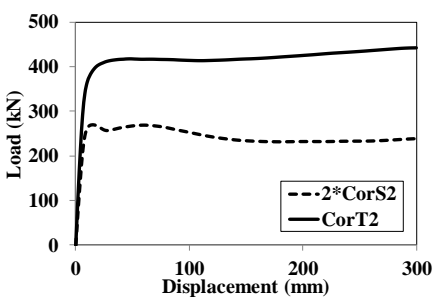

(b) CorS2 and CorT2

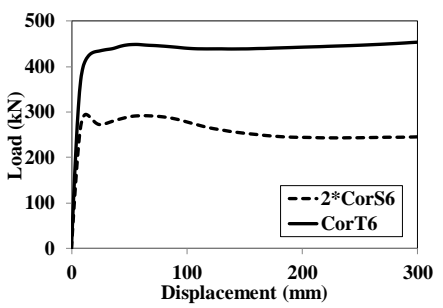

(f) CorS6 and CorT6

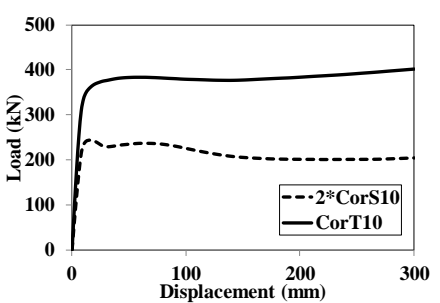

(j) CorS10 and CorT10

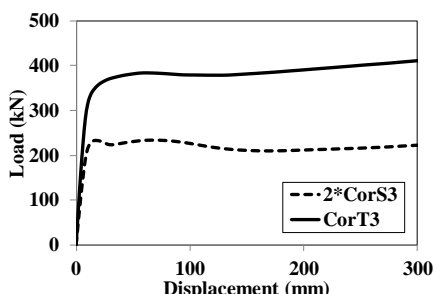

(c) CorS3 and CorT3

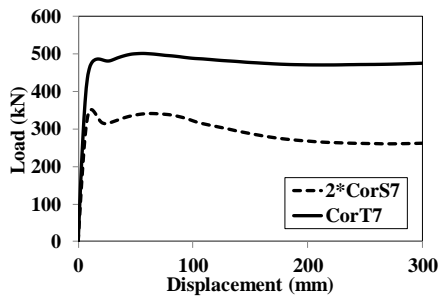

(g) CorS7 and CorT7

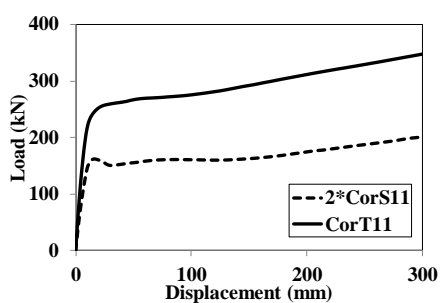

(k) CorS11 and CorT11

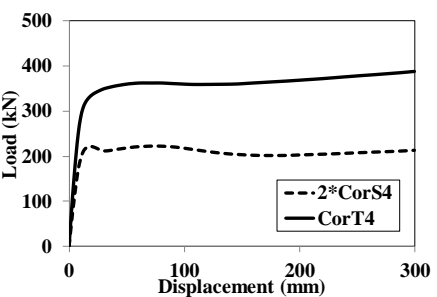

(d) CorS4 and CorT4

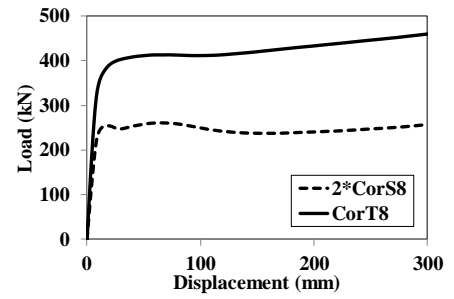

(h) CorS8 and CorT8

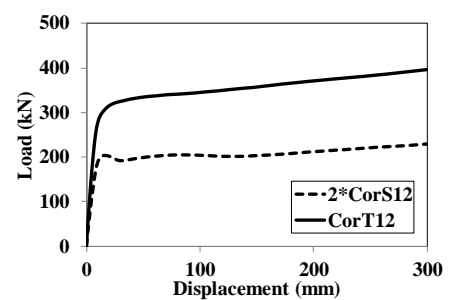

(1) CorS12 and CorT12

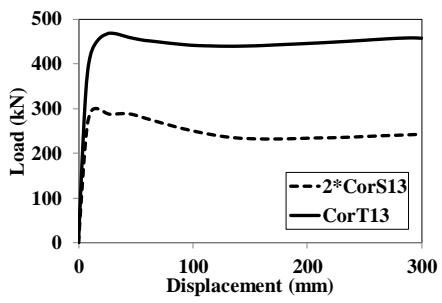

(m) CorS13 and CorT13

Fig. 18 Comparisons of the resistance-displacement curves for CorS-series and CorT-series substructures

\section{Conclusions}

This paper proposed an analytical method to quantify the progressive collapse resistance for composite multi-storey framed-structures due to an edge-column loss. Parametric studies were launched to evaluate the performance of the proposed analytical method. The contributions of vierendeel effect to the progressive collapse resistance of multi-storey structures in different edge-column loss scenarios were further analyzed. The following conclusions can be drawn from this study:

(1) The proposed method can be used to predict the collapse resistance of the multi-storey composite structures due to an edge-column loss, with errors within $15 \%$.

(2) It is recommended in practical design to obtain the ultimate bearing capacity of structures due to an EC column loss based on the yield-line theory.

(3) For EI column loss, the vierendeel effect enhances the progressive collapse resistance of structures with limited extents. Thus, it is conservative and acceptable to obtain the progressive collapse resistance of multi-storey structures based on that of single-storey structures without considering the vierendeel effect.

(4) For EC column loss, the vierendeel effect increases the progressive collapse resistance by more than $60 \%$. It is thus over conservative to obtain the resistance of multi-storey structures merely from that of single-storey structures where no vierendeel effect is considered.

\section{Acknowledgements}

The work presented in this paper was supported by the Thirteen-Five Science and Technology Support Program with grant 2016YFC0701203. 


\section{References}

[1] Pearson C, Delatte N., "Ronan point apartment tower collapse and its effect on building codes", Journal of Performance of Constructed Facilities, 19(2), 172-177, 2005.

[2] Corley W.G., Sr P.F.M., Sozen M.A. and Thornton C.H., "The Oklahoma City Bombing Summary and Recommendations for Multihazard Mitigation", Journal of Performance of Constructed Facilities, 12(3), 100-112, 1998

[3] Bazant Z.P. and Zhou Y., "Why did the World Trade Center collapse? - Simple analysis", Journal of Engineering Mechanics,128(1), 2-6, 2002.

[4] Jiang B.H., Li G.Q., Li L.L. and Izzuddin B.A., "Experimental Studies on Progressive Collapse Resistance of Steel Moment Frames under Localized Furnace Loading", Journal of Structural Engineering, 144(2), 04017190, 2018.

[5] Johnson E.S., Meissner J.E. and Fahnestock L.A., "Experimental Behavior of a Half-Scale Steel Concrete Composite Floor System Subjected to Column Removal Scenarios". Journal of Structural Engineering, 142, 040151332, 2016

[6] Demonceau J.F. and Jaspart J.P., "Experimental Test Simulating a Column Loss in a Composite Frame", Advanced Steel Construction, 6(3), 891-913, 2011

[7] Guo L., Gao S., Fu F. and Wang Y., "Experimental study and numerical analysis of progressive collapse resistance of composite frames", Journal of Constructional Steel Research, 89, 236-251, 2013.

[8] Fu Q.N., Tan K.H., Zhou X.H. and Yang B., "Three-Dimensional Composite Floor Systems under Column-Removal Scenarios", Journal of Structural Engineering, 144(10), 04018196 , 2018

[9] Nethercot D.A., Stylianidis P., Izzuddin B.A. and Elghazouli A.Y., "Enhancing the Robustness of Steel and Composite Buildings", Advanced Steel Construction, 7(1), 64-85(SI), 2011.

[10] Yu H., Izzuddin B.A. and Zha X.X., "Progressive Collapse of Steel-Framed Buildings: Influence of Modelling Approach", Advanced Steel Construction, 6(4), 932-948, 2010.
[11] Alashker Y., El-Tawil S. and Sadek F., "Progressive Collapse Resistance of Steel-Concrete Composite Floors", Journal of Structural Engineering, 136, 1187-1196, 2010

12] Li H.H., and El-Tawil S., "Three-Dimensional Effects and Collapse Resistance Mechanisms in Steel Frame Buildings", Journal of Structural Engineering, 140(8), A4014017, 2014

[13] Izzuddin B.A., Vlassis A.G., Elghazouli A.Y. and Nethercot D.A., "Progressive collapse of multi-storey buildings due to sudden column loss - Part I: Simplified assessment framework", Engineering Structures, 30, 1308-1318, 2008.

[14] Li G.Q., Zhang J.Z. and Jiang J., "Analytical Modeling on Collapse Resistance of Stee Beam-Concrete Slab Composite Substructures Subjected to Side Column Loss", Engineering Structures, 169, 238-255, 2018.

[15] Alashker Y. and El-Tawil S., "A design-oriented model for the collapse resistance of composite floors subjected to column loss", Journal of Constructional Steel Research, 67, 84-92, 2011.

[16] Zhang J.Z. and Li G.Q., "Collapse resistance of steel beam-concrete slab composite substructures subjected to middle column loss", Journal of Constructional Steel Research, $145,471-488,2018$.

[17] Department of Defense (DoD). Unified facilities criteria (UFC): design of structures to resist progressive collapse, Washington (DC), 2010

[18] Park R. and Gamble W.L., "Reinforced concrete slabs. USA: John Wiley \& Sons Inc; 2000

[19] Hu H.C., Variational principles of elastic mechanics and their applications, China, Science Press, 1981.

[20] Yi W.J., Zhang F.Z. and Kunnath S.K., "Progressive Collapse Performance of RC Flat Plate Frame Structures", Journal of Structural Engineering, 140, 040140489, 2014.

[21] ABAQUS Analysis User's Manual Version 6.7., ABAQUS Inc, 2007. 